\title{
Comparação entre fibroblastos gengivais e do ligamento periodontal de um mesmo indivíduo
}

\section{Comparison between gingival and periodontal ligament fibroblasts from the same subject}

\author{
Daniela Bazan Palioto* \\ Ricardo Della Coletta** \\ Hercílio Martelli Júnior*** \\ Julio Cesar Joly* \\ Edgard Graner** \\ Antonio Fernando Martorelli de Lima****
}

\begin{abstract}
RESUMO: O objetivo deste estudo foi comparar as características morfológicas, o potencial proliferativo e a produção protéica de fibroblastos do ligamento periodontal (FLP) e de fibroblastos gengivais (FG). Os fibroblastos foram cultivados pela técnica do explante a partir de fragmentos da gengiva e do ligamento periodontal de um mesmo indivíduo. As células foram isoladas e plaqueadas para análise por microscopia de contraste de fase e microscopia óptica. O índice de proliferação celular foi determinado por contagem automática de células e pelo ensaio de incorporação de bromodioxiuridina (BrdU). A produção de proteina total foi verificada por eletroforese em gel de poliacrilamida e o perfil enzimático por análise zimográfica. Os FLP são maiores e mais alongados que os FG em condições de subconfluência e confluência celular. Os FLP demonstraram um potencial proliferativo significantemente maior que os FG. Os perfis protéico e enzimático foram similares entre os FLP e FG. Os resultados demonstram que os FLP e FG são diferentes na morfologia e na capacidade proliferativa, porém são semelhantes na produção protéica.
\end{abstract}

DESCRITORES: Fibroblastos; Bolsa gengival; Ligamento periodontal.

\begin{abstract}
The objective of this study was to compare fibroblasts from the periodontal ligament (PLF) and gingival fibroblasts (GF) as to morphology, proliferation rate and protein synthesis. PLF and GF were explanted from tissues of the same patient. To characterize and compare the morphology of cells, PLF and GF were plated and analyzed under phase-contrast and optical microscopies. Proliferation rates were determined by means of automated counts carried out in days 1, 4, 7, 15 and 21, and also by means of the bromodeoxyuridine labelling index (BrdU). Total protein content was analyzed by means of electrophoresis in $10 \%$ polyacrylamide gel and zimography containing gelatin as substrate. PLF were bigger and more elongated than GF in subconfluence and confluence conditions. The proliferative rate of PLF was higher than that of GF at 1, 4, and 7 days ( $<$ 0.05). At 15 and 21 days, there was no statistically significant difference as to the number of cells. PLF presented a significantly greater proliferative potential, in relation to GF $(p<0.05)$. The synthesis of protein in a period of 24 hours was similar for both PLF and GF. Our results demonstrated that PLF and GF are different as to morphology and proliferative capacity, however, they do not differ as to protein synthesis.
\end{abstract}

DESCRIPTORS: Fibroblasts; Gingival pocket; Periodontal ligament.

\section{INTRODUÇÃO}

A doença periodontal é um processo inflamatório caracterizado pela perda dos tecidos de suporte, incluindo o ligamento periodontal, cemento e osso alveolar ${ }^{4}$. A partir da publicação de Melcher ${ }^{9}$ (1976), demonstrando que o ligamento periodontal contém células com potencial regenerativo, o principal objetivo dos tratamentos periodontais tem sido a regeneração dos tecidos de suporte perdidos. A indução e diferenciação de fibroblastos do ligamento periodontal favorece o processo regenerativo com a formação de novo cemento, ligamento periodontal e osso alveolar em área anteriormente envolvida pela doença ${ }^{8}$. Sendo assim, a caracterização e comparação das células do ligamento periodontal com células de outros tecidos tem sido essencial para o melhor conhecimento da partici-

*Pós-Graduandos do Departamento de Prótese e Periodontia, Área de Periodontia; **Professores Assistentes Doutores do Departamento de Diagnóstico Oral, Área de Patologia; ***Pós-Graduando do Departamento de Diagnóstico Oral, Área de Patologia; **** Professor Titular do Departamento de Prótese e Periodontia, Área de Periodontia - Faculdade de Odontologia de Piracicaba da Universidade Estadual de Campinas. 
Palioto DB, Coletta RD, Martelli Júnior H, Joly JC, Graner E, Lima AFM de. Comparação entre fibroblastos gengivais e do ligamento periodontal de um mesmo indivíduo. Pesqui Odontol Bras 2002;16(4):319-325.

pação destas células no processo de regeneração periodontal.

As características morfológicas e biológicas dos fibroblastos dos tecidos periodontais não são completamente conhecidas, e os resultados de estudos de cultura celulares variam. Fibroblastos do ligamento periodontal (FLP) são morfologicamente semelhantes, mas funcionalmente diferentes dos fibroblastos gengivais (FG) ${ }^{6}$. Por exemplo, os FLP produzem grandes quantidades de fosfatase alcalina ${ }^{5}$, enzima que atua no metabolismo do fosfato, provavelmente iniciando o processo de mineralização óssea e formação do cemento acelular ${ }^{1}$. Os FLP parecem proliferar mais rapidamente e sintetizar maiores quantidades de matriz extracelular que os $\mathrm{FG}^{7,13}$. Estas características não são exclusivas das células do ligamento periodontal, entretanto constituem atributos funcionais importantes nos processos regenerativos. Para auxiliar na elucidação das diferenças entre os FLP e FG, o objetivo deste estudo foi comparar as características morfológicas, o potencial proliferativo e a produção protéica de fibroblastos isolados do ligamento periodontal e da gengiva de um mesmo indivíduo.

\section{MATERIAIS E MÉTODOS \\ Culturas primárias de FLP e FG}

Os fragmentos do ligamento periodontal foram obtidos de pré-molares extraídos por razão ortodôntica de uma paciente de 12 anos de idade e os fragmentos gengivais foram obtidos aproveitando o retalho levantado para realização da extração. O estudo foi aprovado pelo Comitê de Ética em Pesquisa da Faculdade de Odontologia de Piracicaba UNICAMP.

As culturas primárias de FLP e FG foram obtidas pela técnica do explante como descrito por Somerman et al. ${ }^{13}$ (1988) com algumas modificações. Os pré-molares extraídos foram lavados gentilmente com soro fisiológico e com auxílio de uma cureta foi removido o ligamento periodontal do terço médio da raiz. O material foi plaqueado em meio Eagle modificado por Dulbecco (DMEM; Sigma Chemical Co., St. Louis, MO, EUA) complementado com $150 \mu \mathrm{g} / \mathrm{ml}$ de ampicilina G e 10\% de soro fetal bovino (SFB; Gibco BRL, Gaithersburg, MD, EUA) em uma placa de $35 \mathrm{~mm}$ de diâmetro (Corning Cortar, EUA). Os fragmentos gengivais foram cortados em fragmentos de aproximadamente $1 \mathrm{~mm}^{3}$, lavados e incubados no mesmo meio de cultura em frasco de $25 \mathrm{~cm}^{2}$ (Corning Costar). As culturas foram mantidas à temperatura de $37^{\circ} \mathrm{C}$, em atmosfera úmida contendo $5 \%$ de $\mathrm{CO}_{2}$. O crescimento celular foi monitorado e o meio de cultura trocado a cada 2 dias. A concentração de ampicilina $\mathrm{G}$ foi reduzida para $50 \mu \mathrm{g} / \mathrm{ml}$ após 15 dias de cultivo. Ao atingirem a confluência, as células foram subcultivadas. Para as subculturas, as células foram lavadas em salina tamponada com fosfato (PBS) acrescida de 0,1\% EDTA, tratadas com solução de tripsina a $0,1 \%$ e transferidas para frascos de cultura de $75 \mathrm{~cm}^{2}$, caracterizando a primeira passagem (P1). Os experimentos foram realizados utilizando as células entre a primeira e décima passagens.

\section{Análise morfológica}

Fibroblastos do ligamento periodontal e fibroblastos gengivais ( $10^{5}$ células) foram plaqueados em $3 \mathrm{ml}$ de DMEM acrescido de 10\% de SFB em frascos de cultura de $75 \mathrm{~cm}^{2}$ e mantidos a $37^{\circ} \mathrm{C}$, em atmosfera úmida contendo $5 \%$ de $\mathrm{CO}_{2}$ por $24 \mathrm{~h}$. Em seguida, as células foram incubadas com meio de cultura fresco por períodos que variaram de 1 a 5 dias. Diariamente as células foram analisadas em condições de subconfluência e confluência, em microscópio de fase invertido.

\section{Índice de crescimento celular}

Fibroblastos do ligamento periodontal e fibroblastos gengivais ( $3 \times 10^{4}$ células / "well”) foram plaqueados em $2 \mathrm{ml}$ de DMEM acrescido de 10\% de SFB e cultivados em placas de cultura de 24 "wells" a $37^{\circ} \mathrm{C}$ em atmosfera úmida contendo $5 \%$ de $\mathrm{CO}_{2}$. Transcorridas $16 \mathrm{~h}$, as células foram lavadas com PBS e o meio de cultura substituído por DMEM sem SFB. Após 16 h, as células foram novamente incubadas com DMEM acrescido de $10 \%$ de SFB. O índice de crescimento celular foi determinado por contagem da população celular no $1^{\circ}$, $4^{\circ}, 7^{\circ}, 15^{\circ}$ e $21^{\circ}$ dias, usando um contador automático de células (Coulter Counter, Beckman).

\section{Índice proliferativo de incorporação de BrdU}

Fibroblastos do ligamento periodontal e fibroblastos gengivais $\left(3 \times 10^{4}\right)$ foram plaqueados em 0,5 $\mathrm{ml}$ de DMEM acrescido de 10\% de SFB em lâminas de vidro tratadas para cultura celular (LabTek, Nunc Int, Naperville, IL, EUA) e cultivados a $37^{\circ} \mathrm{C}$ em atmosfera úmida contendo $5 \% \mathrm{CO}_{2}$ por $24 \mathrm{~h}$. Em seguida, as células foram lavadas em PBS e incubadas em mesmo meio acrescido de BrdU (Amersham Life Sci, Arlington, IL, EUA) na diluição 1:1.000. Após $1 \mathrm{~h}$ de incorporação de BrdU as células em proliferação foram reveladas 
Palioto DB, Coletta RD, Martelli Júnior H, Joly JC, Graner E, Lima AFM de. Comparação entre fibroblastos gengivais e do ligamento periodontal de um mesmo individuo. Pesqui Odontol Bras 2002;16(4):319-325.

por análise imuno-histoquímica utilizando protocolos descritos pelo fabricante (kit de proliferação celular, Amersham). O índice de incorporação foi expresso como porcentagem de células marcadas com BrdU e representada a contagem de 500 células de cada linhagem celular, utilizando o sistema de análise de imagens Zeiss (KONTROM 400).

\section{Análise da produção protéica}

Fibroblastos do ligamento periodontal e fibroblastos gengivais foram plaqueados em duplicata em placas de 24 "wells" ( $6 \times 10^{4}$ células/"well") e cultivados por $24 \mathrm{~h}$. Em seguida, as células foram tratadas com DMEM acrescido ou não de $10 \%$ de SFB e cultivadas por um período adicional de $24 \mathrm{~h}$. Os sobrenadantes celulares foram coletados e as células incubadas em tampão de lise contendo $50 \mathrm{mM}$ de Tris-HCl, pH 8,0; $5 \mathrm{mM}$ de EDTA; 1\% Tween de 20; 2 mM de PMSF; 2 mM de NEM sob agitação a $4^{\circ} \mathrm{C}$ por $30 \mathrm{~min}$. Após rápida centrifugação, o sobrenadante e o extrato celular tiveram a concentração protéica total determinada pelo método de Bradford (Bradford ${ }^{2}$, 1976).

\section{Eletroforese em gel de poliacrilamida}

Quantidades iguais de proteinas dos sobrenadantes ou dos extratos celulares das culturas de FLP e FG foram misturadas com tampão de amostra redutor $(2 \%$ de SDS; $125 \mathrm{mM}$ de Tris- $\mathrm{HCl}$, $\mathrm{pH} 8,0 ; 10 \%$ de glicerol; 0,001\% de azul de bromofenol; $2 \%$ de mercaptoetanol), fervidas por $5 \mathrm{~min}$, submetidas à separação eletroforética em gel de poliacrilamida a $10 \%$ (SDS-PAGE) e coradas em Coomassie blue R 250 (Bio Rad Lab., Hercules, CA, EUA).

\section{Zimografia}

A análise zimográfica foi realizada como descrita por Coletta et $a .^{3}{ }^{3}$ (1999). Resumidamente, a mesma quantidade protéica dos sobrenadantes ou dos extratos celulares das culturas de FLP e FG foram incubadas com tampão de amostra não redutor e submetidas à eletroforese em 10\% SDS-PAGE contendo $1,6 \mathrm{mg} / \mathrm{ml}$ de gelatina (Bio Rad) como substrato. Após eletroforese, os géis foram lavados duas vezes por 30 min em solução aquosa de $2 \%$ de Triton X-100 e incubados por $16 \mathrm{~h}$ a $37^{\circ} \mathrm{C}$ em tampão de ativação composto por $10 \mathrm{mM}$ de Tris- $\mathrm{HCl} \mathrm{pH}$ 8,0 e $5 \mathrm{mM}$ de $\mathrm{CaCl}_{2}$. A seguir, os géis foram corados com Coomassie blue R 250 (Bio $\mathrm{Rad})$. As proteínas com atividade gelatinolítica foram observadas como bandas negativas. Para confirmação da identidade das enzimas com atividade gelatinolítica como pertencentes ao grupo das metaloproteinases de matriz (MMP) foi adicionado ao tampão de ativação $2 \mathrm{mM}$ de 1,10-fenantrolina (Sigma), um inibidor específico da ação enzimática de MMPs.

\section{Análise estatística}

Os resultados foram expressos como média \pm desvio padrão dos grupos de fibroblastos. Para análise das diferenças entre os grupos foi utilizado o teste $t$ de Student com critério bicaudal, utilizando 5\% como nivel de significância. Todos os experimentos foram realizados, pelo menos, três vezes.

\section{RESULTADOS}

Fibroblastos do ligamento periodontal e fibroblastos gengivais emergiram dos fragmentos em média 7 dias após o início da cultura. Contudo, devido ao maior número e tamanho dos fragmentos gengivais em comparação aos fragmentos do ligamento periodontal, após 2 semanas de cultura primária, as FG preenchiam mais de $70 \%$ do frasco, sendo então realizada a primeira subcultura. Por outro lado, a primeira subcultura de FLP só foi possivel após 70 dias de cultivo primário. As células da gengiva e do ligamento periodontal proliferaram em orientação paralela respeitando o espaço entre as membranas celulares. Em condições de confluência celular não foram observados empilhamento, desorganização ou morte celular. Ocorreu inibição de crescimento por contato, como é característico de células normais. Após a décima primeira passagem foi observada uma redução na velocidade de crescimento e, próximo a décima quinta passagem, as duas culturas não progrediram como inicialmente, sendo então descartadas.

\section{Morfologia celular}

Em condições de subconfluência e de confluência, os fibroblastos do ligamento periodontal e gengivais exibiram formato fusiforme com núcleo central e típicos prolongamentos citoplasmáticos, entretanto, aparentemente, as células provenientes do ligamento periodontal apresentaram dimensões maiores e eram mais alongadas do que as oriundas da gengiva (Figura 1). Em condições de saturação celular, o número de $\mathrm{FG}$ variou entre 16,2 e $26,2 \times 10^{4}$ células $/ \mathrm{cm}^{2}$ com a média de $21,1 \pm 4,3 \times 10^{4}$ células $/ \mathrm{cm}^{2}$, enquanto que o número de FLP variou entre 11,4 e $19,8 \times 10^{4}$ células $/ \mathrm{cm}^{2}$ com uma média de $15,9 \pm 3,5 \times 10^{4}$ cé- 
Palioto DB, Coletta RD, Martelli Júnior H, Joly JC, Graner E, Lima AFM de. Comparação entre fibroblastos gengivais e do ligamento periodontal de um mesmo indivíduo. Pesqui Odontol Bras 2002;16(4):319-325.

FIGURA 1 -

Características

morfológicas em

microscopia de

contraste de fase dos

fibroblastos gengivais

(FG) (A e C) e

fibroblastos do

ligamento periodontal

(FLP) (B e D). A e B

representam condições

de subconfluência

celular enquanto que

$\mathrm{C}$ e D representam condições de

confluência. Note o

típico formato

fusiforme de ambos os

tipos celulares em condições de subconfluência celular. Em condições de confluência, FLP demonstraram

dimensões maiores que FG (160 X).
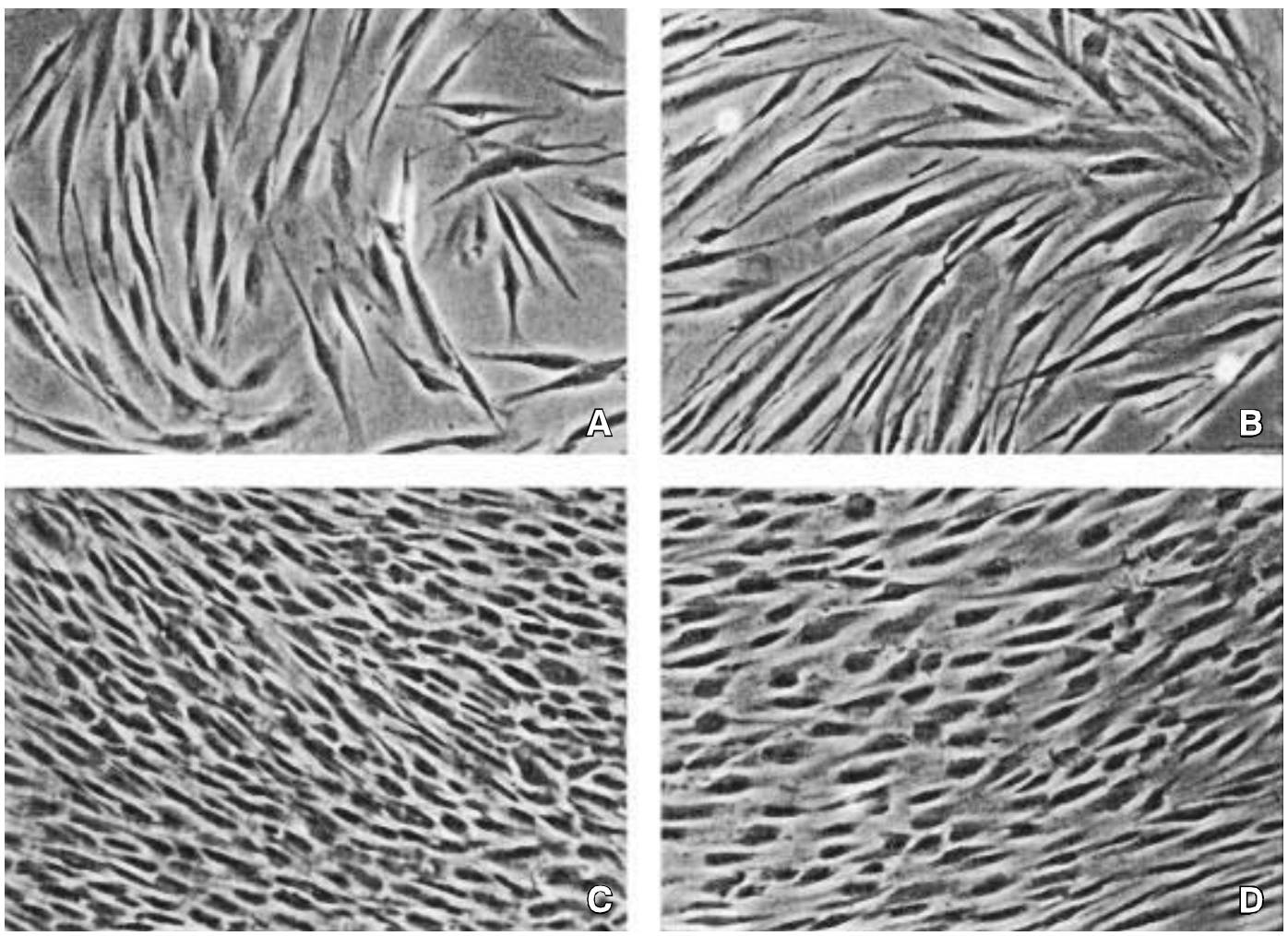

TABELA 1 - Análise proliferativa determinada pelo índice de incorporação de BrdU e contagem celular em confluência máxima por $\mathrm{cm}^{2}$ para fibroblastos do ligamento periodontal (FLP) e fibroblastos gengivais (FG).

\begin{tabular}{c|c|c}
\hline \hline Fibroblastos & BrdU (\%) & Células $\left(\times 10^{4}\right) / \mathrm{cm}^{2}$ \\
\hline FLP & $65,1 \pm 11,0^{*}$ & $15,9 \pm 3,5$ \\
\hline FG & $41,2 \pm 17,1$ & $21,1 \pm 4,3^{*}$ \\
\hline \hline
\end{tabular}

${ }^{*} \mathrm{p}<0,05$.

lulas $/ \mathrm{cm}^{2}$. O número de $\mathrm{FG} / \mathrm{cm}^{2}$ foi significativamente maior que o número de FLP ( $\mathrm{p}<0,05$; Tabela 1).

\section{Proliferação celular}

A análise proliferativa dos FLP e FG é mostrada no Gráfico 1. FLP proliferaram mais rapidamente em todos os períodos analisados. Do dia 1 ao 7 as diferenças no número de células entre os grupos foram estatisticamente significantes $(p<0,05)$. Nos dias 15 e 21 foi observada uma saturação no número de células, sendo a proliferação menos intensa. O índice de incorporação de BrdU também demonstrou que FLP apresentam maior potencial proliferativo que FG. A imunorreatividade para BrdU foi identificada em ambas as culturas celulares. Nú-

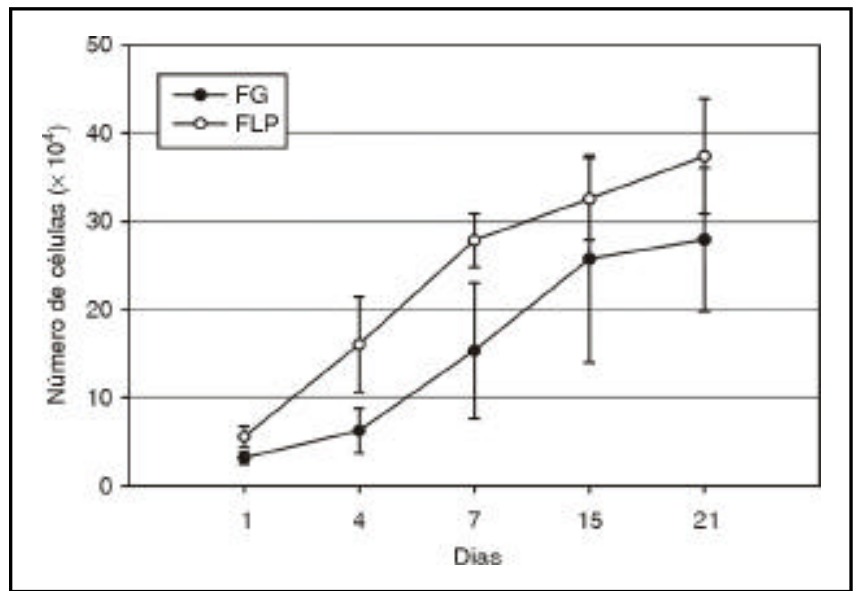

GRÁFICO 1 - Relação de crescimento celular para fibroblastos do ligamento periodontal (FLP) e fibroblastos gengivais (FG). Cada ponto representa a média \pm desvio padrão de 9 contagens independentes para cada linhagem celular. Do dia 1 ao dia 7 as diferenças no número de FLP foram significantemente maiores que de FG $(p<0,05)$. Nos dias 15 e 21 foi observada uma saturação na quantidade de células.

cleos com coloração marrom, independente da intensidade de marcação, identificaram as células em proliferação. A Tabela 1 demonstra que FLP apresentaram indice de incorporação de BrdU significativamente maior que $\mathrm{FG}(\mathrm{p}<0,05)$. A porcentagem 
Palioto DB, Coletta RD, Martelli Júnior H, Joly JC, Graner E, Lima AFM de. Comparação entre fibroblastos gengivais e do ligamento periodontal de um mesmo individuo. Pesqui Odontol Bras 2002;16(4):319-325.

média de células do ligamento periodontal positivas para BrdU foi $65,1 \pm 11,0 \%$, com mediana de $63,6 \%$, enquanto que FG apresentaram média de $41,2 \pm 17,1 \%$, com uma mediana de $43,6 \%$.

\section{Produção protéica}

A análise da produção protéica total determinada em gel de eletroforese em gel de poliacrilamida a $10 \%$ demonstrou um padrão similar para FLP e FG cultivados na presença ou ausência de SFB, no período de $24 \mathrm{~h}$ (Figura 2). Quando o sobrenadante e o extrato celular de FLP e FG foram analisados por eletroforese em gel de poliacrilamida contendo gelatina como substrato, foi identificada uma banda com atividade gelatinolitica de massa molecular aproximadamente a $72 \mathrm{kDa}$ (Figura 3). A atividade enzimática foi inibida por 1,10-fenantrolina, indicando que esta enzima provavelmente corresponde a metaloproteinase de matriz-2 (MMP-2). Não

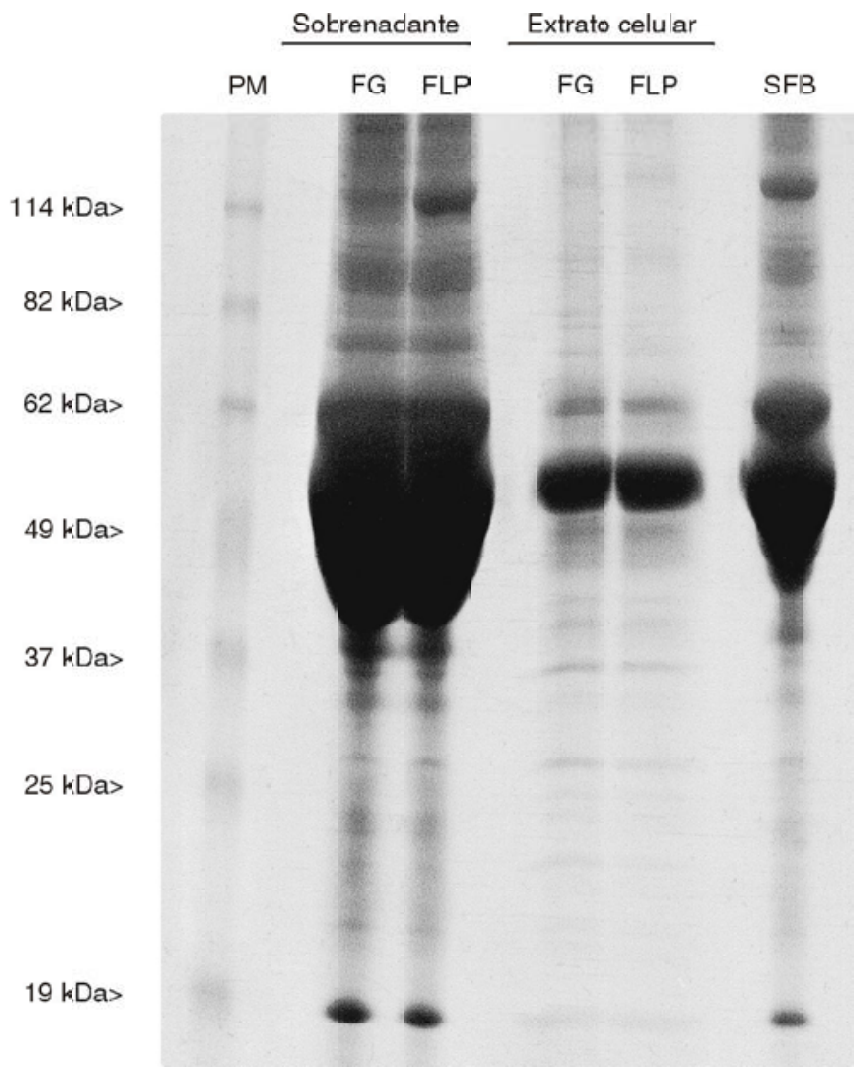

FIGURA 2 - Análise da produção de proteína total em fibroblastos do ligamento periodontal (FLP) e fibroblastos gengivais (FG). As células foram cultivadas por $24 \mathrm{~h}$ e o sobrenadante e extrato celulares foram submetidos à separação eletroforética em gel de poliacrilamida a 10\%. O padrão de peso molecular (PM) é indicado a esquerda do gel. Meio de cultura suplementado com $10 \%$ de soro fetal bovino foi utilizado como controle da reação. foi observada diferença na produção entre as linhagens celulares, porém o sobrenadante demonstrou uma maior atividade gelatinolítica.

\section{DISCUSSÃO}

A caracterização das células do ligamento periodontal e sua comparação com células do tecido gengival são essenciais para a compreensão dos sucessos e insucessos da manutenção e regeneração periodontal. As características morfológicas e bioquímicas dos FLP são ainda pouco conhecidas. Neste estudo, nós utilizamos culturas primárias de FLP e FG isoladas de um mesmo indivíduo. Este fato é fundamental para a comparação fenotípica entre as linhagens celulares, visto que as características genéticas são idênticas. FLP apresentaram características distintas dos FG. Em condições de subconfluência e confluência celular, a morfologia dos FLP e FG foi diferente. FLP foram mais alonga-

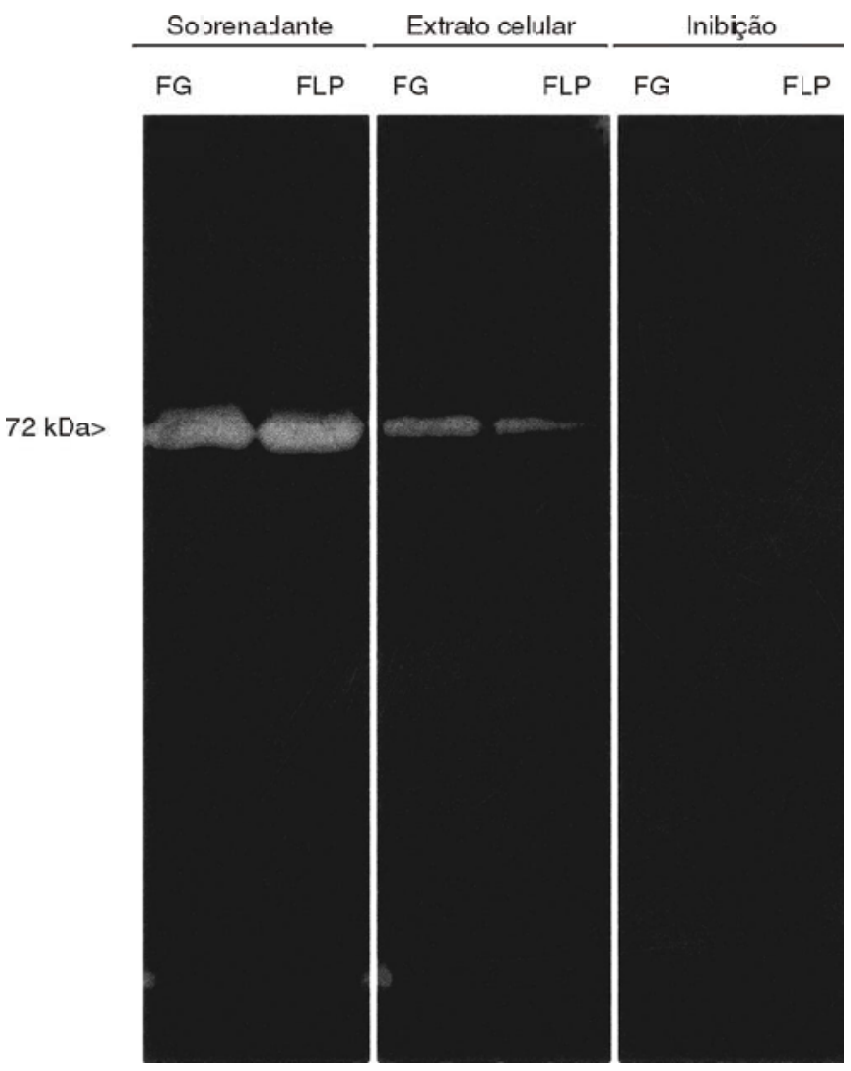

FIGURA 3 - Análise zimográfica em gel de poliacrilamida co-polimerizado com gelatina dos sobrenadantes de culturas celulares de fibroblastos do ligamento periodontal (FLP) e fibroblastos gengivais (FG). Observe a presença de uma enzima com atividade gelatinolitica de massa molecular estimada em $72 \mathrm{kDa}$ e com atividade inibida por 1,10 fenantrolina nos sobrenadantes de FG e FLP, correspondendo a metaloproteinase de matriz-2. 
Palioto DB, Coletta RD, Martelli Júnior H, Joly JC, Graner E, Lima AFM de. Comparação entre fibroblastos gengivais e do ligamento periodontal de um mesmo indivíduo. Pesqui Odontol Bras 2002;16(4):319-325.

dos e volumosos que FG. Em condições de saturação da densidade celular, o número de FLP por $\mathrm{cm}^{2}$ foi significantemente menor comparado ao de FG. O potencial proliferativo dos FLP foi maior que o dos FG. Por outro lado, a produção protéica total e a atividade gelatinolitica foram similares nas linhagens celulares estudadas.

Existem poucos trabalhos na literatura avaliando e comparando as características dos FLP com FG de um mesmo paciente. Apesar de Hassel $^{6}$ (1993) ter afirmado que os fibroblastos do ligamento periodontal são semelhantes aos gengivais, pudemos observar, ao microscópio de contraste de fase, que na cultura de FLP existe predominância de células maiores e mais alongadas em comparação à cultura de FG (Figura 1). Estes resultados estão de acordo com os resultados observados por Ogata et al. ${ }^{10}$ (1995) que demonstraram que, em condições de confluência, FLP humanos são mais afilados que os FG.

$O$ indice de proliferação determinado pela contagem celular foi estatisticamente mais alto nos dias 1, 4 e 7 para os FLP que para os FG (Gráfico 1). Nos dia 15 e 21 os fibroblastos do ligamento periodontal ainda proliferaram mais que os gengivais, sem diferença estatística significativa, possivelmente pelo fato de ambas as linhagens estarem atingindo a confluência. Isso pode ser confirmado pela análise proliferativa pelo índice de incorporação de BrdU. O índice BrdU para FLP foi de $61 \%$ enquanto que para os $\mathrm{FG}$ foi de $43 \%(\mathrm{p}<0,05)$ (Tabela 1). Estes resultados indicam crescimento exponencial mais rápido para os FLP, que segundo Mariotti e Cochran ${ }^{7}$ (1990) atingem um platô de confluência em 6 dias.
A presença da enzima fosfatase alcalina é descrita nos FLP, mas não nos $\mathrm{FG}^{11,12}$. Arceo et al. ${ }^{1}$ (1991) demostraram que a enzima fosfatase alcalina é fundamental para o início da mineralização cementária, promovendo a formação dos núcleos de mineralização.

A produção de proteína total durante o período de $24 \mathrm{~h}$ demonstrou um perfil protéico similar para FLP e FG, tanto qualitativa quanto quantitativamente. Para melhor caracterização deste perfil protéico, as linhagens celulares foram submetidas a análise zimográfica, revelando a presença de uma enzima com atividade gelatinolítica de massa molecular aproximadamente de $72 \mathrm{kDa}$, correspondendo a MMP-2 (Figura 3). Nossos resultados estão de acordo com os verificados por Mariotti e Cochran $^{7}$ (1990), que usaram culturas isoladas de pacientes diferentes e encontraram síntese de proteína total e de colágeno similar para os dois grupos celulares no período de $24 \mathrm{~h}$. Por outro lado, estes resultados são contrários aos achados de Somerman et al..$^{13}$ (1988), que também usaram linhagens do mesmo paciente e encontraram uma produção maior de proteína total e colágeno para os FLP em comparação aos FG.

\section{CONCLUSÃO}

Os resultados desta análise comparativa indicam que os FLP são maiores e mais alongados e mostraram índice de proliferação mais acelerado que os FG. Entretanto, a produção de proteína total e a atividade gelatinolítica foram similares para os dois grupos celulares.

\section{AGRADECIMENTOS}

Este trabalho foi financiado pela Fundação de Apoio a Pesquisa do Estado de São Paulo FAPESP, processos 99/10767-8 e 99/04921-4.

\section{REFERÊNCIAS}

1. Arceo N, Sauk JJ, Moehring J, Foster RA, Somerman MJ. Human periodontal cells initiate mineral-like nodules in vitro. J Periodontol 1991;62(8):499-503.

2. Bradford MM. A rapid and sensitive method for the quantitation of microgram quantities of protein utilizing the principle of protein-dye binding. Anal Biochem 1976;72(7):248-54.

3. Coletta RD, Almeida OP, Reynolds MA, Sauk JJ. Alteration in expression of MMP-1 and MMP-2 but not TIMP- 1 and TIMP-2 in hereditary gingival fibromatosis is mediated by TGF-beta 1 autocrine stimulation. J Periodontal Res 1999;34(8):457-63.

4. Gestrelius S, Andersson C, Lidstrom D, Hammarstrom L, Somerman MJ. In vitro studies on periodontal ligament

cells and enamel matrix derivative. J Clin Periodontol 1997;24(9):685-92.

5. Groeneveld MC, Everts V, Beertsen W. Formation of afibrillar acellular cementum-like layers induced by alkaline phosphatase activity from periodontal ligament explants maintained in vitro. J Dent Res 1994;73(10):1588-92.

6. Hassel TM. Tissues cells of the periodontium. Periodontol 2000 1993;3:9-38.

7. Mariotti A, Cochran DL. Characterization of fibroblasts derived from human periodontal ligament and gingiva. $\mathrm{J} P e-$ riodontol 1990;61(2):103-111.

8. McCulloch CA. Basic considerations in periodontal wound healing to achieve regeneration. Periodontol 2000 1993;(1):16-25. 
Palioto DB, Coletta RD, Martelli Júnior H, Joly JC, Graner E, Lima AFM de. Comparação entre fibroblastos gengivais e do ligamento periodontal de um mesmo individuo. Pesqui Odontol Bras 2002;16(4):319-325.

9. Melcher AH. On the repair potential of periodontal tissues. J Periodontol 1976;47(5):256-60.

10. Ogata Y, Niisato N, Sakurai T, Furuyama S, Sugiya H. Comparison of the characteristics of human gingival fibroblasts and periodontal ligament cells. J Periodontol 1995;66(12):1025-31.

11. Piche JE, Carnes DL, Graves DT. Initial characterization of cells derived from human periodontia. J Dent Res 1989;68(5):761-7.
12. San Miguel SM, Goseki-Sone M, Sugiyama E, Watanabe H, Yanagishita M. The effects of retinoic acid on alkaline phosphatase activity and tissue-non-specific alkaline phosphatase gene expression in human periodontal ligament cells and gingival fibroblasts. J Periodontal Res 1998;33(7):428-33.

13. Somerman MJ, Archer SY, Imm GM, Foster RA. A comparative study of human periodontal ligament cells and gingival fibroblasts in vitro. J Dent Res 1988;67(1):66-70.

Recebido para publicação em 15/08/01 Enviado para reformulação em 23/08/02 Aceito para publicação em 17/09/02 